\title{
Electroless deposition, post annealing and characterization of nickel films on silicon
}

\author{
SUBIR SABHARWAL ${ }^{\dagger}$, , SIDDHARTH PALIT ${ }^{\dagger}, \mathrm{R}$ B TOKAS, A K POSWAL* and \\ SANGEETA* \\ Spectroscopy Division, *Crystal Technology Laboratory, TPPED, Bhabha Atomic Research Centre, \\ Mumbai 400 085, India \\ ${ }^{\dagger}$ Department of Metallurgical \& Materials Engineering, Indian Institute of Technology, Roorkee 247 667, India \\ • Currently at: Department of Physics, Columbia University, New York, USA
}

MS received 9 December 2007; revised 31 March 2008

\begin{abstract}
Electroless deposition of nickel (EN) films on $n$-type silicon has been investigated under different process conditions. The interface between the film and substrate has been characterized for electrical properties by probing the contact resistances. $X$-ray diffraction and atomic force microscopy have been performed to obtain information about the structural and morphological details of the films. As a comparative study, nickel films have also been sputter deposited on silicon substrates. An as-deposited electroless film is observed to form non-ohmic contact while in a sputtered film prepared without the application of substrate heating, the formation of metal-insulating-semiconductor type junction is seen.
\end{abstract}

Keywords. Electroless deposition; X-ray diffraction; scanning probe microscopy; nickel film.

\section{Introduction}

The electroless deposition is a promising method to prepare durable metal films on both conducting and non-conducting substrates of different geometries (Brenner and Riddell 1946; Chow et al 1997; Jeon and Paik 2002; Liu et al 2006). There are several applications of the electroless deposited films and among them their use as electrical contacts has been widely exploited. Here, the coatings must have a good combination of electrical conductivity, wearing characteristics, resistance to erosion and weldability. The electroless coatings of nickel meet most of these criteria and hence have been widely investigated and constantly improved upon to suit various applications (Haichuan et al 2003; Libo et al 2006). Recently, Liu et al (2005) studied the interfacial reactions of electroless nickel (EN) films on silicon arising due to annealing in the temperature range $300-900^{\circ} \mathrm{C}$, employing TEM and measurement of sheet resistance. However, the changes in the electrical properties of the interfacial layer between silicon and EN film with deposition conditions and/or thermal treatment have not been investigated in literature.

In this communication, we investigate (i) the effect of thermal treatment on the electrical contact resistance of the interface formed between the EN film and the silicon substrate and (ii) film microstructure. In order to gain a

*Author for correspondence (sangita@barc.gov.in) better insight on these two issues, nickel films were also deposited by RF magnetron sputtering technique without the application of substrate heating and characterized along with EN films primarily to bring out the beneficial role of the hydrogen evolved during EN deposition on the electrical characteristics of the film substrate interface. The interfaces of films deposited by two techniques were found to display different electrical characteristics. Also, they exhibited quite different morphological and adhesion properties. For sputtered films, the changes observed in RMS surface roughness on thermal annealing were found to be insignificant. However, significant changes were observed for the EN films, which were larger for films deposited at higher $\mathrm{pH}$. The observed variation in the roughness values in the two cases has been understood in terms of the coverage of nucleating centres on the growing surface which gives rise to the formation of different shapes and sizes of the localized grain clusters.

\section{Experimental}

\subsection{Electroless deposition}

The process involves selective reduction of metal ions on a solid surface through autocatalytic redox reaction. This is achieved through the presence of particular ions like the hypophosphite in the solution. The hypophosphite ions readily react with water to give orthophosphate ions and active hydrogen atoms in the presence of a catalytic solid 
Table 1. Process conditions for electroless deposited films.

\begin{tabular}{lllcr}
\hline Solution & \multicolumn{1}{c}{ Purpose } & Concentration & $\begin{array}{c}\text { Dip time } \\
(\mathrm{min})\end{array}$ & $\begin{array}{c}\text { Temperature } \\
\left({ }^{\circ} \mathrm{C}\right)\end{array}$ \\
\hline Stannous chloride & Sensitization & $0 \cdot 5 \mathrm{~g} / 100 \mathrm{ml}$ & $1-10$ & 25 \\
Palladium chloride & Activation & $0 \cdot 1 \mathrm{mg} / \mathrm{litr}$ & $2-20$ & 25 \\
Nickel sulphate + & Nickel deposition by & $\mathrm{NiSO}_{4}$ & $1-10$ & 65 \\
sodium succinate + & electroless technique & $2 \mathrm{~g} / 100 \mathrm{ml}$ & & \\
sodium hypophosphite & & $\mathrm{NaH}_{2} \mathrm{PO}_{2}$ & \\
& & $2 \cdot 7 \mathrm{~g} / 100 \mathrm{ml}$ & \\
& & $\mathrm{Na}_{2} \mathrm{C}_{4} \mathrm{H}_{4} \mathrm{O}_{4}$ & \\
& $1 \cdot 6 \mathrm{~g} / 100 \mathrm{ml}$ & \\
\hline
\end{tabular}

surface. The hydrogen atom with its unshared pair of electrons act as an active species, readily reducing the metal ions i.e. $\mathrm{Ni}^{2+}$ ions, in the case of nickel deposition to atomic nickel thus evolving hydrogen gas in the process. Since the reaction described takes place at the solid surface and hence the metal atoms thus formed get deposited on the solid surface/substrate. As the newly deposited film would itself act as the catalyst and hence this process is autocatalytic enabling film deposition of any thickness. In addition to the reaction leading to the metal deposition, there are other reactions also simultaneously taking place in the solution and for the successful metal deposition it is imperative to exert a control on them.

One of the reactions that takes place is between the active hydrogen atoms and the hypophosphite ions resulting in the formation of elemental phosphorus. The elemental phosphorus thus formed gets incorporated into the lattice of the metal film thereby resulting into a nanocomposite structure. The percentage of phosphorus incorporated may vary over a large range depending upon the solution characteristics and hence the degree of its effect on the metal deposition will significantly differ depending upon the solution $\mathrm{pH}$. Summarizing, the temperature, $\mathrm{pH}$ and concentration of hypophosphite ions in solution are the three basic process variables governing the properties of metal film (Liu et al 2005). Other process parameters, viz. the dipping time and deposition temperature control the average roughness, thickness, and adhesion properties.

In our experiments, $\langle 100\rangle$ oriented $n$-type silicon wafers were used. Prior to deposition they were subjected to standard piranha cleaning process. Subsequently, they were first sensitized in a solution of $\mathrm{SnCl}_{2}$ and then activated by dipping in a solution of $\mathrm{PdCl}_{2}$. After thorough rinsing with DI water, they were dipped in the EN bath for nickel deposition. The components of the bath consisted of sodium hypophosphite, nickel sulphate, and sodium succinate. The $\mathrm{pH}$ and temperature of the bath were varied in our initial experiments to obtain good quality films on silicon as determined by the visual inspection. The concentrations of various components used and the variation in the $\mathrm{pH}$ and temperature of the bath are given in table 1 . The thickness of films deposited was found to be in the range of $0.8-1.5 \mu \mathrm{m}$. The film thickness was measured by an ultra precision measurement centre Model: UPMC 850 Zeiss.
Nickel films were also deposited by RF magnetron sputtering technique. Here, an RF frequency of $13.56 \mathrm{MHz}$ and $75 \mathrm{~mm}$ diameter magnetron cathode were employed to sputter deposit Ni films on silicon substrates. The system used was equipped with necessary mass flow controller and quartz crystal monitor to accurately monitor the gas pressure and film thickness, respectively. The films were deposited under pure argon atmosphere at the rate of $1 \AA / \mathrm{s}$ and employing no deliberate substrate heating. The films used in the present investigation were typically of $1 \mu \mathrm{m}$ thickness.

The films were subjected to thermal treatment in a furnace which could be first evacuated to $10^{-6}$ torr vacuum and then filled with pure argon to avoid film oxidation. A Eurotherm make temperature controller cum programmer was employed for a controlled thermal treatment of the films.

\subsection{Structural and electrical characterization}

A Rigaku Dmax-2200 X-ray diffractometer, employing a $\mathrm{CuK} \alpha$ beam $(\lambda=1.5418 \AA)$ was used to investigate the structural changes arising due to variations in deposition parameters and/or thermal treatment under argon. The current-voltage characteristics of the interface region were studied by using two contact points: one on the film and the other on the silicon substrate. The contacts were taken out using silver wires and silver paste and it should be mentioned that their contact resistances and the contribution of the substrate surface resistance could not be avoided in the present measurements.

\subsection{Atomic force microscopy}

The film topographies before and after annealing were investigated by atomic force microscopy (AFM) (Ralston et al 2005). The AFM investigations were made employing NT-MDT Solver P-47H multi-mode ambient based scanning probe microscope. The cantilever used was a $\mathrm{Si}_{3} \mathrm{~N}_{4}$ with typical spring constant of $0.6 \mathrm{~N} / \mathrm{m}$ and resonant frequency of $75 \mathrm{kHz}$. The measurements were carried out in contact mode operation without any image filtering technique for the topographic measurements. For Fourier 


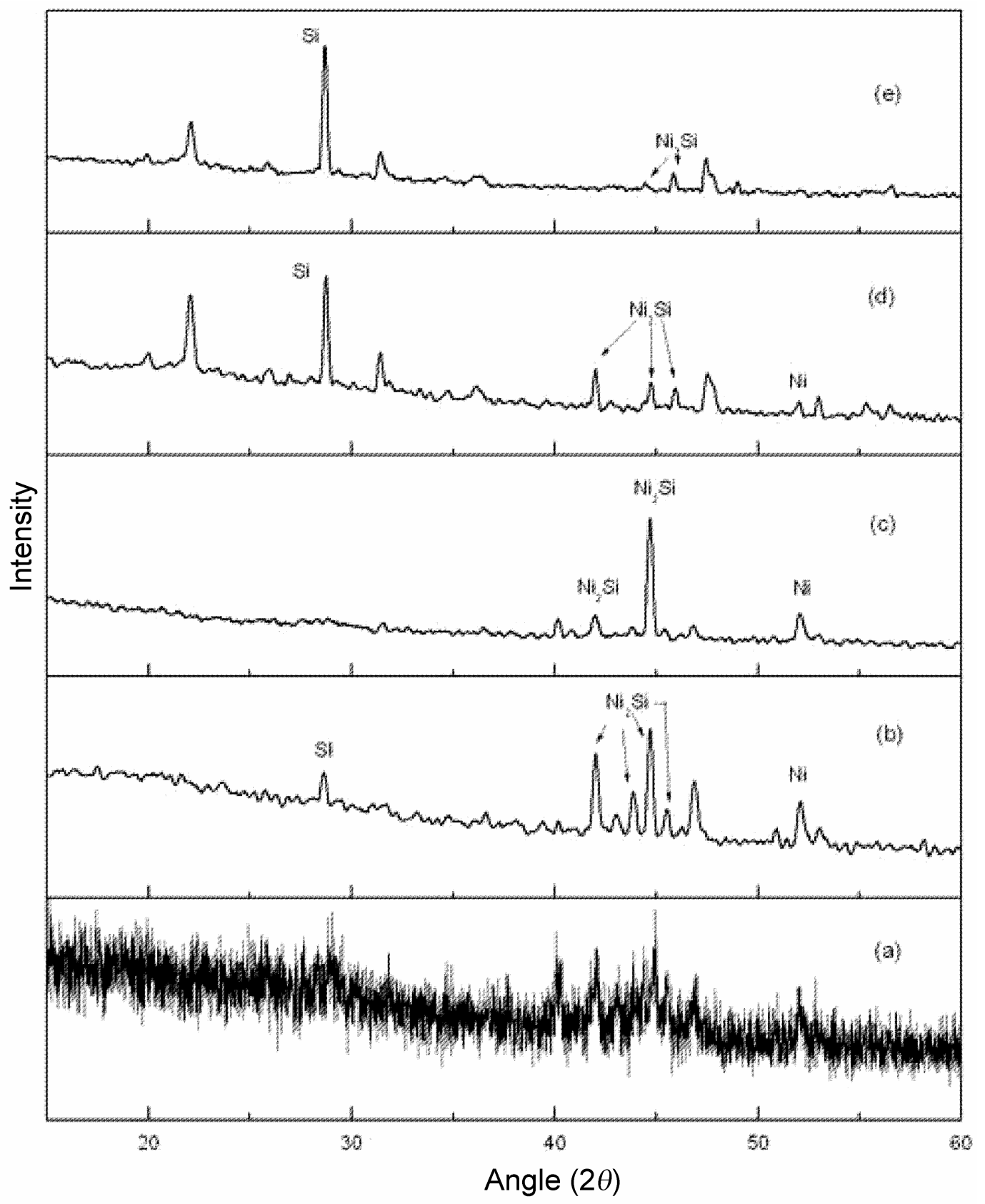

Figure 1. Typical X-ray diffraction patterns of nickel films deposited by electroless method: (a) as deposited film, (b) film 1 annealed at $500^{\circ} \mathrm{C}$, (c) film 2 annealed at $500^{\circ} \mathrm{C}$, (d) film 1 annealed at $900^{\circ} \mathrm{C}$ and (e) film 2 annealed at $900^{\circ} \mathrm{C}$. Films 1 and 2 were deposited at pH 4.92 and 9.46, respectively.

analysis, the built in fast Fourier transform module of the control software NOVA-SPM was employed to generate the mappings. In order to have the consistency in the experimental results, the same cantilever was used for all the morphological as well as force-distance microscopy measurements. The films used in this study had a coated area of $1.5 \mathrm{~cm}^{2}$ and thickness, $\sim 1 \mu \mathrm{m}$. In order to find out the RMS roughness, a total of ten measurements at different locations on the film surface were made to get the mean RMS value for each film. In all cases the RMS roughness determined at any point on film surface was found to be within $10 \%$ of the mean value.

\section{Results}

In our initial experiments, the depositions were carried out for different dip times and deposition temperatures over a range and the films were subjected to a visual examination. The films deposited for dip times of 5-10 min and solution temperatures in the range of $60-75^{\circ} \mathrm{C}$ were found 
to be good. Hence, in the subsequent experiments these parameters were fixed and the effect of solution $\mathrm{pH}$ in the range of 4-10 on film characteristics was investigated. The as-deposited films showed shining black appearance, smooth texture and reasonably good adhesion on $n$-type silicon.

\section{$3.1 X$-ray diffraction}

Figure 1 shows the X-ray diffraction patterns for films deposited from solutions of two extreme $\mathrm{pH}$ values, viz. 4.92 (film 1) and 9.46 (film 2), recorded before and after annealing at $500^{\circ} \mathrm{C}$ and $900^{\circ} \mathrm{C}$ for $30 \mathrm{~min}$ under argon atmosphere. A typical XRD plot shown in figure 1(a) reveals the amorphous nature of as-deposited films. The pattern obtained for the two films after annealing at $500^{\circ} \mathrm{C}$ are shown as plots (b) and (c) in figure 1. From these measurements, the following observations could be made.

- The high temperature annealing carried out at $500^{\circ} \mathrm{C}$ is observed to promote the formation of crystalline structure in both the films, as evidenced by the presence of diffraction peaks in plots (b) and (c) of figure 1.

- Irrespective of solution $\mathrm{pH}$, the formation of $\mathrm{Ni}_{2} \mathrm{Si}$ is confirmed by the prominent diffraction peaks corresponding to $2 \theta$ values of $42.42,43.53,44.33$ and $45.53^{\circ}$, in plots (b) and (c) of figure 1 (JCPDS file 48-1339). Peaks at $2 \theta$ equal to 28.63 and $52^{\circ}$ correspond to that of Si (JCPDS 77-2107) and Ni (JCPDS 87-0712), respectively. The diffraction peak at $2 \theta$ equal to $47^{\circ}$ however, could not be identified from the crystallographic data available in literature.

The XRD patterns were also recorded for films 1 and 2 after annealing them at $900^{\circ} \mathrm{C}$ to investigate any further change occurring due to film-substrate reaction. The data obtained for the two films are shown as plots (d) and (e) of figure 1. For both the films, while all the diffraction peaks, as also observed after $500^{\circ} \mathrm{C}$ annealing are seen, some additional peaks corresponding to $2 \theta$ values of $22.1^{\circ}$ and $31.4^{\circ}$ are also observed. These results clearly show enhanced reaction between the film and silicon on raising the annealing temperature.

The films were processed under argon atmosphere and hence the formation of nickel oxide was not expected. This point was confirmed by the XRD measurements shown in figure 1 . The strong reflections of $\mathrm{NiO}$ corresponding to $2 \theta$ values of $43 \cdot 28^{\circ}$ and $37 \cdot 25^{\circ}$ (JCPDS file 78-0429) or of $\mathrm{NiO}_{2}$ corresponding to $2 \theta$ values of $18.55^{\circ}$ and $37.11^{\circ}, 44.7^{\circ}$ (JCPDS file 85-1977) and that of $\mathrm{Ni}_{2} \mathrm{O}_{3}$ corresponding to $2 \theta$ values of $31.93^{\circ}$ and $39.13^{\circ}, 44.83^{\circ}$, $51.59^{\circ}$ and $56.78^{\circ}$ (JCPDS file 14-0481) were found to be absent in the XRD plots.

The as-deposited sputtered films were also found to be amorphous in nature. However, on annealing at $500^{\circ} \mathrm{C}$ they transformed into crystalline state much like the EN films characterized by plot $\mathrm{b}$ in figure 1 .

\subsection{I-V characteristics}

The current-voltage $(I-V)$ characteristics of the interface layer of as-deposited EN and sputtered films are shown in figures 2 and 3 . The current voltage characteristics of the interface layer formed in films 1 and 2 after annealing at $500^{\circ} \mathrm{C}$ and $900^{\circ} \mathrm{C}$ are shown in figures $4-7$. In figure 8, the $I-V$ characteristics of the interface layer of sputtered film measured after annealing at $500^{\circ} \mathrm{C}$ are shown. From these measurements, the following conclusions could be drawn.

- The contacts formed in the case of as-deposited EN film are non-ohmic, whereas the presence of a junction is inferred in the case of sputtered film.

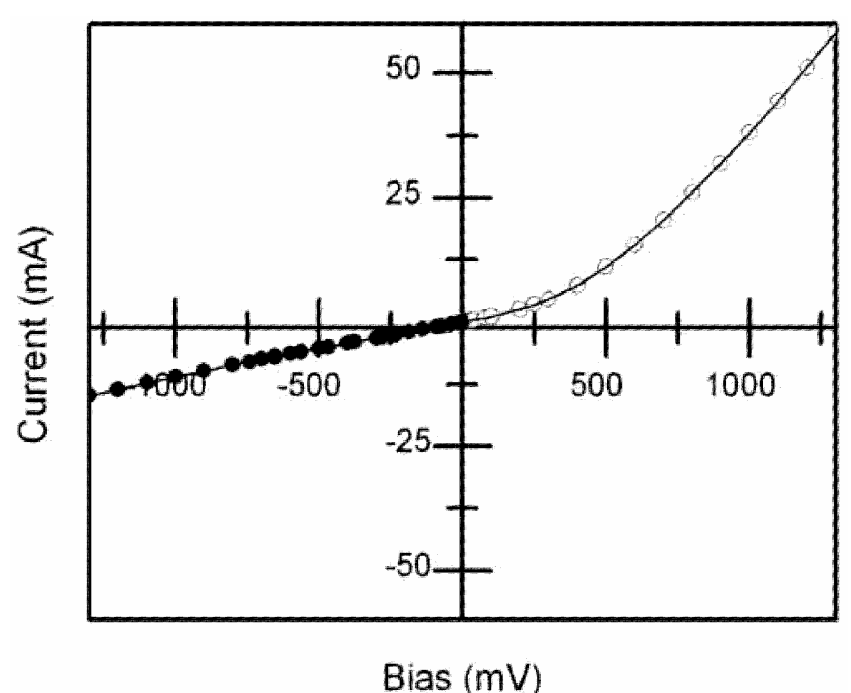

Figure 2. Typical $I-V$ characteristics of an as-deposited electroless nickel film on $n$-type silicon.

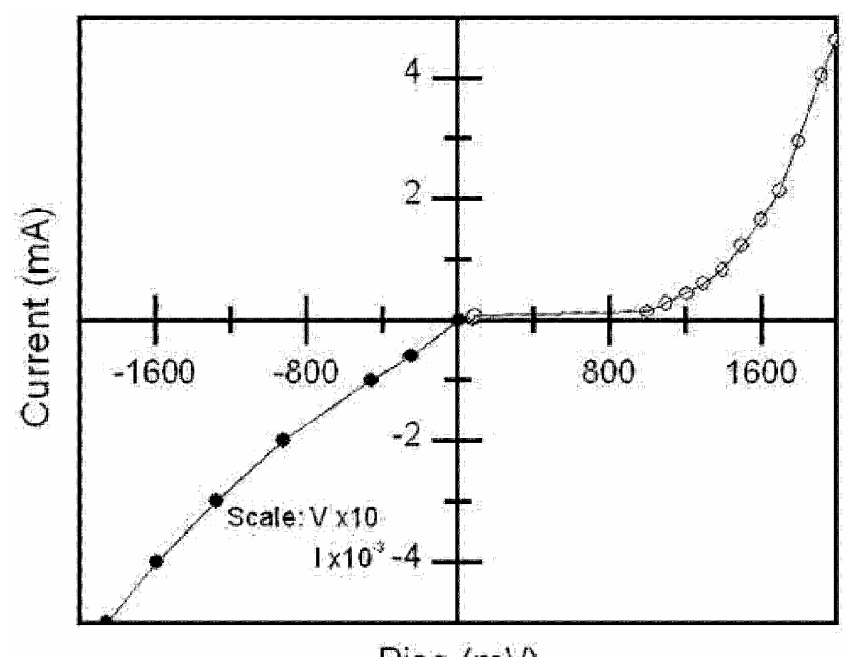

Bias $(\mathrm{mV})$

Figure 3. Typical $I-V$ characteristics of an as-deposited sputtered nickel film on $n$-type silicon. 
- The $I-V$ characteristics of the $500^{\circ} \mathrm{C}$ and $900^{\circ} \mathrm{C}$ annealed films shown in figures 4-5 and 6-7 imply the formation of near ohmic contact.

- The $I-V$ characteristics of the contact formed in case of the sputtered film also show the transformation of a junction to near ohmic contact on annealing at $500^{\circ} \mathrm{C}$, as shown in figure 8 .

\subsection{Film topography and adhesion properties}

The RMS surface roughness measured for the as-deposited films 1 and 2 were 17.07 and $13.14 \mathrm{~nm}$, respectively. Morphological measurements on the same films were repeated

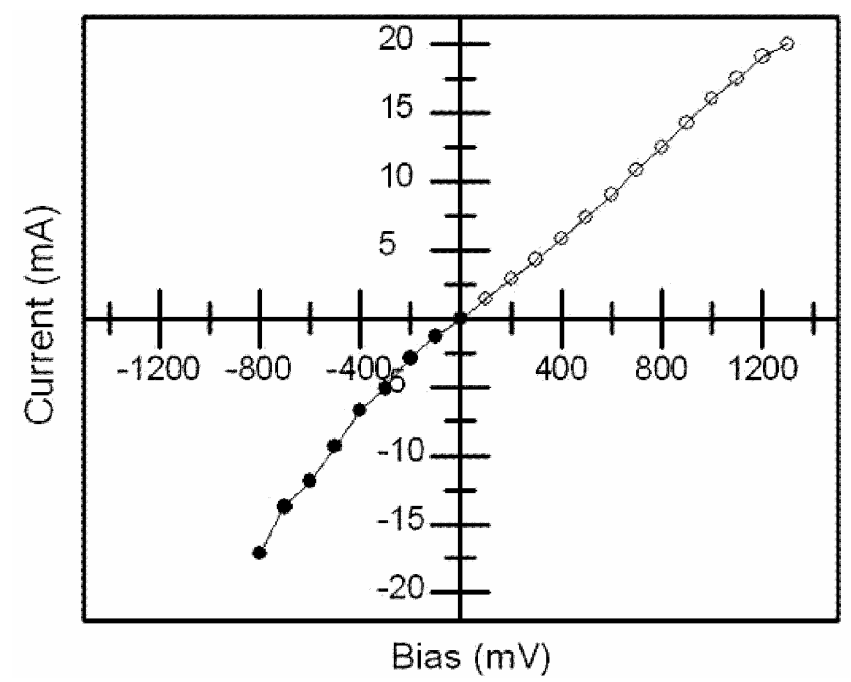

Figure 4. $I-V$ characteristics of the electroless nickel film deposited at $4.92 \mathrm{pH}$ and annealed under argon at $500^{\circ} \mathrm{C}$ for $30 \mathrm{~min}$.

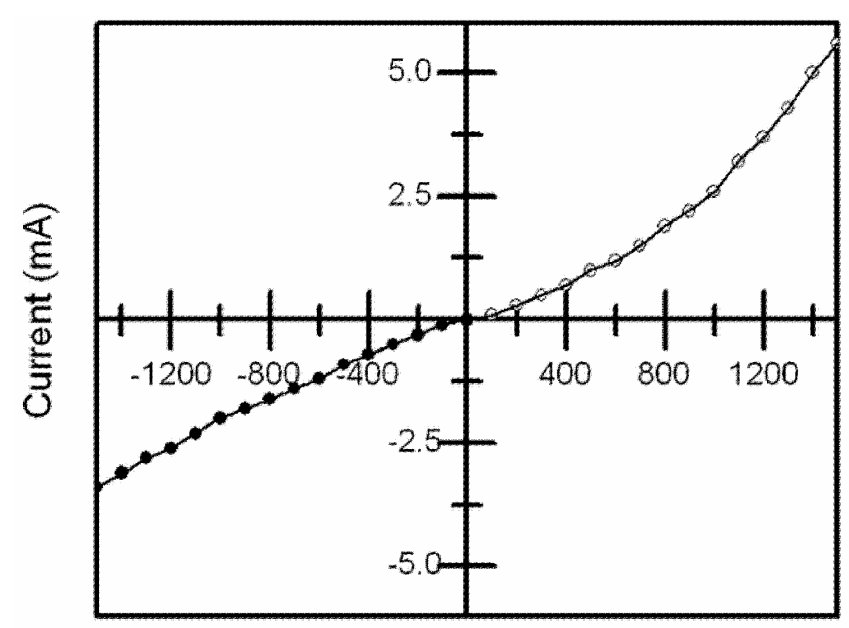

Bias $(\mathrm{mV})$

Figure 5. $I-V$ characteristics of the electroless nickel film deposited at $9.46 \mathrm{pH}$ and annealed under argon at $550^{\circ} \mathrm{C}$ for $30 \mathrm{~min}$. after annealing them at $500^{\circ} \mathrm{C}$. It is interesting to note that the RMS values of surface roughness while in both the cases witnessed an increase; the enhancement observed for film 2 was remarkably high, as shown in table 2 .

The AFM pictures for the as deposited $\mathrm{EN}$ and $500^{\circ} \mathrm{C}$ annealed films are shown in figure 9. The individual grain sizes are found to decrease on annealing resulting in the densification of the films. The observed variation in the roughness values in the two cases was analysed and associated with the formation of different shapes and sizes of the localized grain-clusters or aggregates. On increasing the annealing temperature to $900^{\circ} \mathrm{C}$, the RMS surface

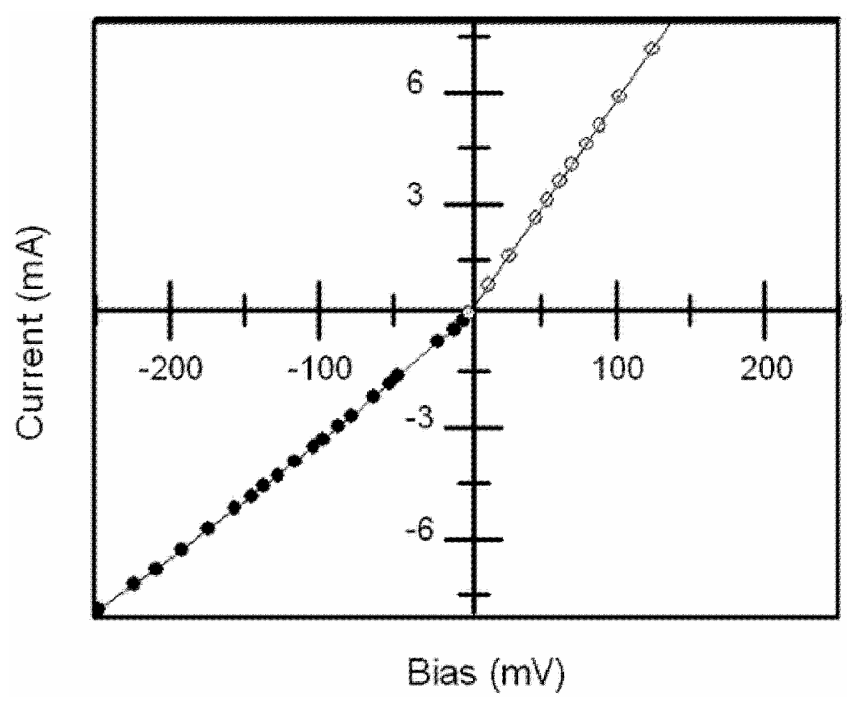

Figure 6. $I-V$ characteristics of the electroless nickel film deposited at $4.92 \mathrm{pH}$ and annealed under argon at $900^{\circ} \mathrm{C}$ for $30 \mathrm{~min}$.

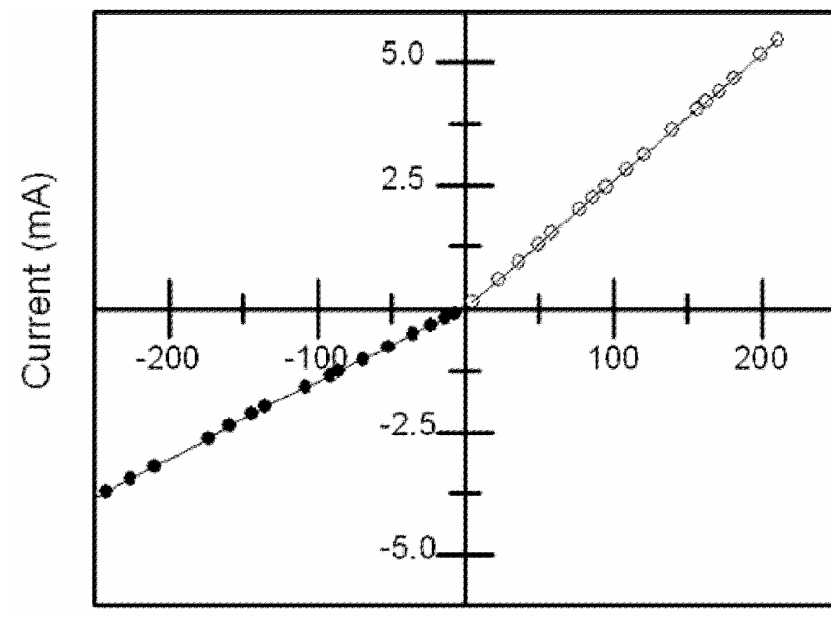

Bias $(\mathrm{mV})$

Figure 7. $I-V$ characteristics of the electroless nickel film deposited at $9.46 \mathrm{pH}$ and annealed under argon at $900^{\circ} \mathrm{C}$ for $30 \mathrm{~min}$. 
Table 2. Effect of thermal annealing on film roughness and adhesion.

\begin{tabular}{lccc}
\hline Sample name & RMS roughness (nm) & $\begin{array}{c}\text { Deflection due to } \\
\text { jump-off-contact (Nm) }\end{array}$ & $\begin{array}{c}\text { Adhesion force } \\
\text { in nano Newton }\end{array}$ \\
\hline Film 1, before annealing & $17 \cdot 07$ & $195 \cdot 0690$ & 19.509 \\
Film 1, after annealing at $500^{\circ} \mathrm{C}$ & $19 \cdot 00$ & $310 \cdot 5923$ & 31.005 \\
Film 2, before annealing & $13 \cdot 14$ & 251.7852 & $25 \cdot 178$ \\
Film 2, after annealing at $500^{\circ} \mathrm{C}$ & $36 \cdot 18$ & $780 \cdot 3723$ & 78.037 \\
Film 1, annealed at $900^{\circ} \mathrm{C}$ & $1 \cdot 45$ & 247.7000 & 24.770 \\
Film 2, annealed at $900^{\circ} \mathrm{C}$ & $12 \cdot 64$ & 344.6650 & 34.463 \\
Film 3, before annealing & $0 \cdot 56$ & 271.4235 & 27.142 \\
Film 3, after annealing at $500^{\circ} \mathrm{C}$ & $0 \cdot 54$ & 365.0065 & 36.500 \\
\hline
\end{tabular}

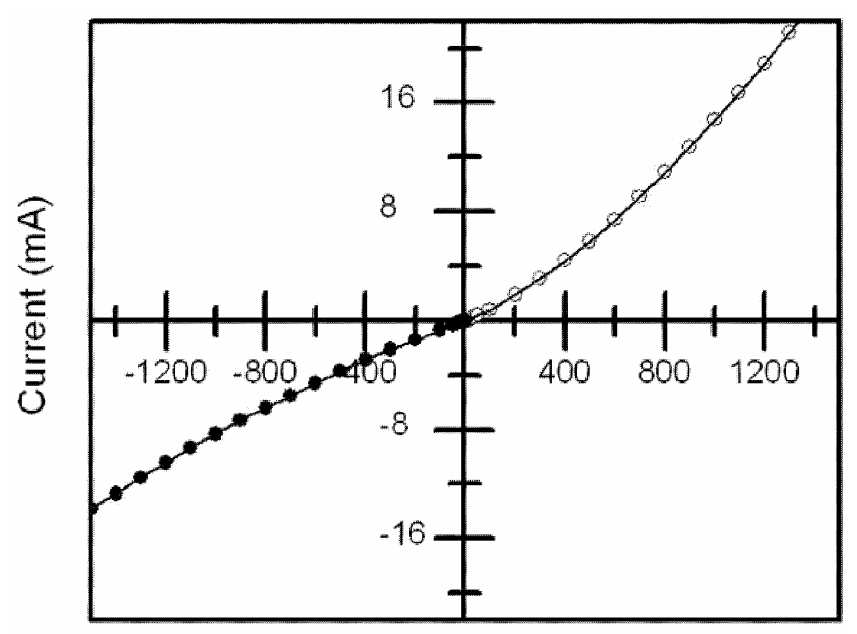

Bias (mV)

Figure 8. $I-V$ characteristics of the sputtered nickel film annealed under argon at $500^{\circ} \mathrm{C}$ for $30 \mathrm{~min}$.

roughness of different samples was found to decrease to a very low value of about $2 \mathrm{~nm}$.

In a typical force spectroscopy schematically shown in figure 10, during the approach of the AFM-tip to a solid sample surface, a 'jump-to-contact' instability occurs just before un-deflected cantilever is brought in contact with the surface under examination. Such a phenomenon is primarily governed by the long-range Van-der-Waals attractive force. During retraction of an AFM-tip pressed against the sample surface it adheres to the surface until the spring force of the cantilever is higher than the attractive interaction force, which undergoes a second instability in terms of 'jump-off-contact'. These two instabilities, which represent the interaction forces between the sample and the probe, depend strongly on the mechanical, elastic and visco-elastic properties of the interacting materials (Wonhee et al 2001).

The adhesion properties computed from the jump-offcontact forces measured from these plots are summarized in table 2. It is noted that on thermal annealing the adhesion force is enhanced. Of course, the increase in adhesion force observed in films 1 and 2 is not uniform.
Further, on thermal annealing a dominant grain-structure transformation from a more disordered amorphous to clustered aggregate formation is clearly borne out from the photographs of figure 9. The RMS roughness and adhesion marginally increased on annealing at $500^{\circ} \mathrm{C}$, implying grain evolution and densification. However, annealing at $900^{\circ} \mathrm{C}$ significantly reduced the RMS roughness due to coalescence of grains. Notably, the annealed samples also have displayed superior electrical contact characteristics of the interface. The microstructure of sputtered films shows that the as deposited films are dense and no significant densification on annealing at $500^{\circ} \mathrm{C}$ takes place (figure 11). The RMS roughness measured for the as-deposited and $500^{\circ} \mathrm{C}$ annealed film is nearly the same and also the increase in adhesion force is small.

\section{Discussion}

A comparative study of the $I-V$ characteristics of nickel films deposited by electroless and sputtering techniques brings out an important result. $I-V$ characteristics reproduced in figures 2 and 3 show the formation of a non-ohmic contact for electroless films and a junction in films sputtered without any substrate heating. These results show the presence of an intermediate insulating layer in the latter case, which is the native surface oxide $\left(\mathrm{SiO}_{2}\right)$ layer on silicon. The absence of this layer in the case of electroless film is explained due to the reaction of the hydrogen gas evolved during deposition with the native oxide thus rendering the silicon surface free from the presence of oxide layer.

An examination of the $I-V$ characteristics of figures 4-7 shows that improvement in the electrical characteristics of interface layer on raising the annealing temperature from $500-900^{\circ} \mathrm{C}$, is not quite significant. On the other hand, the corresponding XRD results show an enhanced reaction between the film and $\mathrm{Si}$ at $900^{\circ} \mathrm{C}$. Hence, in all applications where a sharp boundary between the film and silicon is required, the annealing must be restricted to $500^{\circ} \mathrm{C}$. Of course, the RMS surface roughness in this case would be relatively higher, as revealed by the data of table 2 . From these results it is then inferred that the sele- 

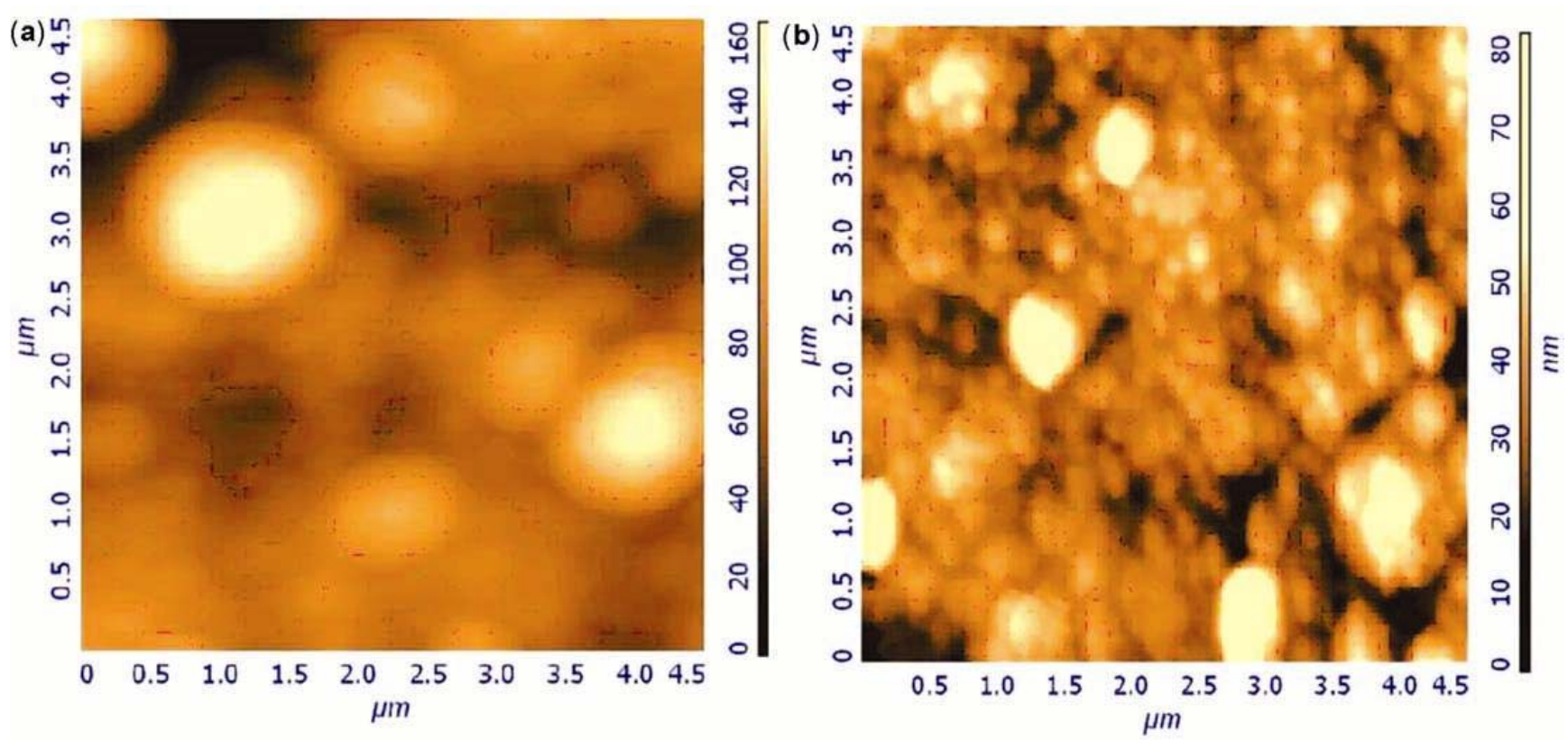

Figure 9. Typical grain structure of the electroless nickel film on $n$-type $\mathrm{Si}$ : (a) as deposited and (b) after annealing at $500^{\circ} \mathrm{C}$.

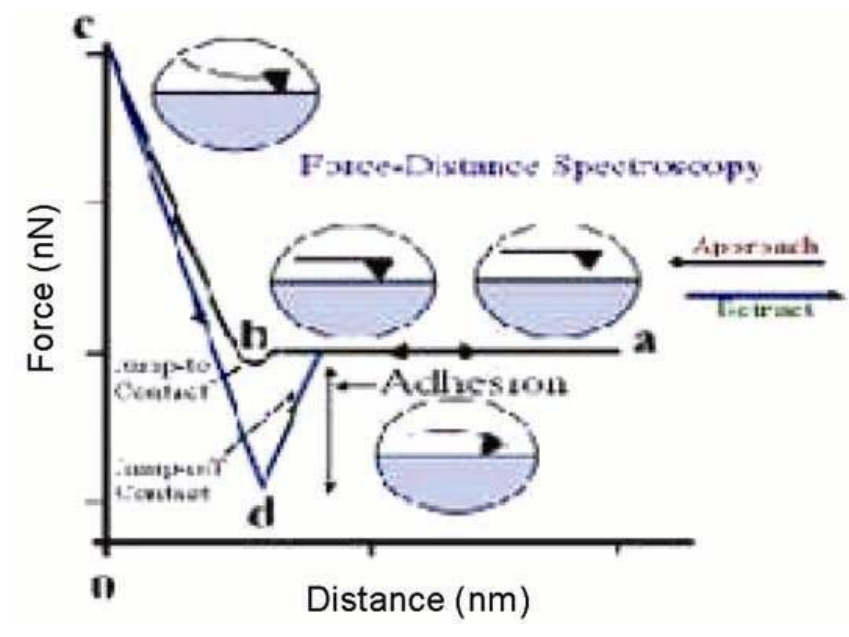

Figure 10. Schematic of force distance spectroscopy showing two major instabilities in terms of jump-into-contact and jumpoff-contacts.

ction of annealing temperature must be guided by the application. Consequently, higher annealing temperature for which the RMS surface roughness is found to dramatically decrease would be suitable for applications requiring very smooth surface.

For sputtered films the changes in RMS roughness observed on annealing are not significant, while in EN films they are found to be appreciable. This difference is attributed to the high kinetic energy of the nickel ions impinging upon the growing surface in the case of sputtering. The impinging ions upon adsorption possess large enough kinetic energy for surface migration which helps the nickel ions to get absorbed at appropriate sites. This promotes the deposition of dense films even without the application of the substrate heating. The micrographs of figure 11 show the growth of a film of nearly uniform grain size and a very small void density.

In case of EN deposition, a small amount of kinetic energy possessed by the depositing ions does not allow the migration of nickel ions upon adsorption and hence the as-deposited films are rough and have large void density. Importantly, the growth here is confined around the nucleating centres. On annealing the grain growth takes place which is reflected by the changes in the RMS roughness and microstructure of films in figure 9. The initial increase in RMS roughness and its subsequent decrease on annealing upon $900^{\circ} \mathrm{C}$ is understood in terms of the individual grain growth to begin with and their ultimate coalescence resulting in smooth topology. The results on films 1 and 2 show the influence of solution $\mathrm{pH}$ on microstructure evolution. The data of table 2 suggests the formation of a lesser degree of nucleating centres in film 2 compared to film 1. Consequently, on annealing while the coated layer can grow vertically in a continuous manner, the lateral growth is restricted due to a larger spacial distance between the individual grains.

\section{Conclusions}

The optimum conditions to prepare adherent nickel films by electroless deposition method on $n$-type silicon have been determined. As a comparative study, nickel films were also deposited by RF magnetron sputtering technique. The important observations made are as follows: 

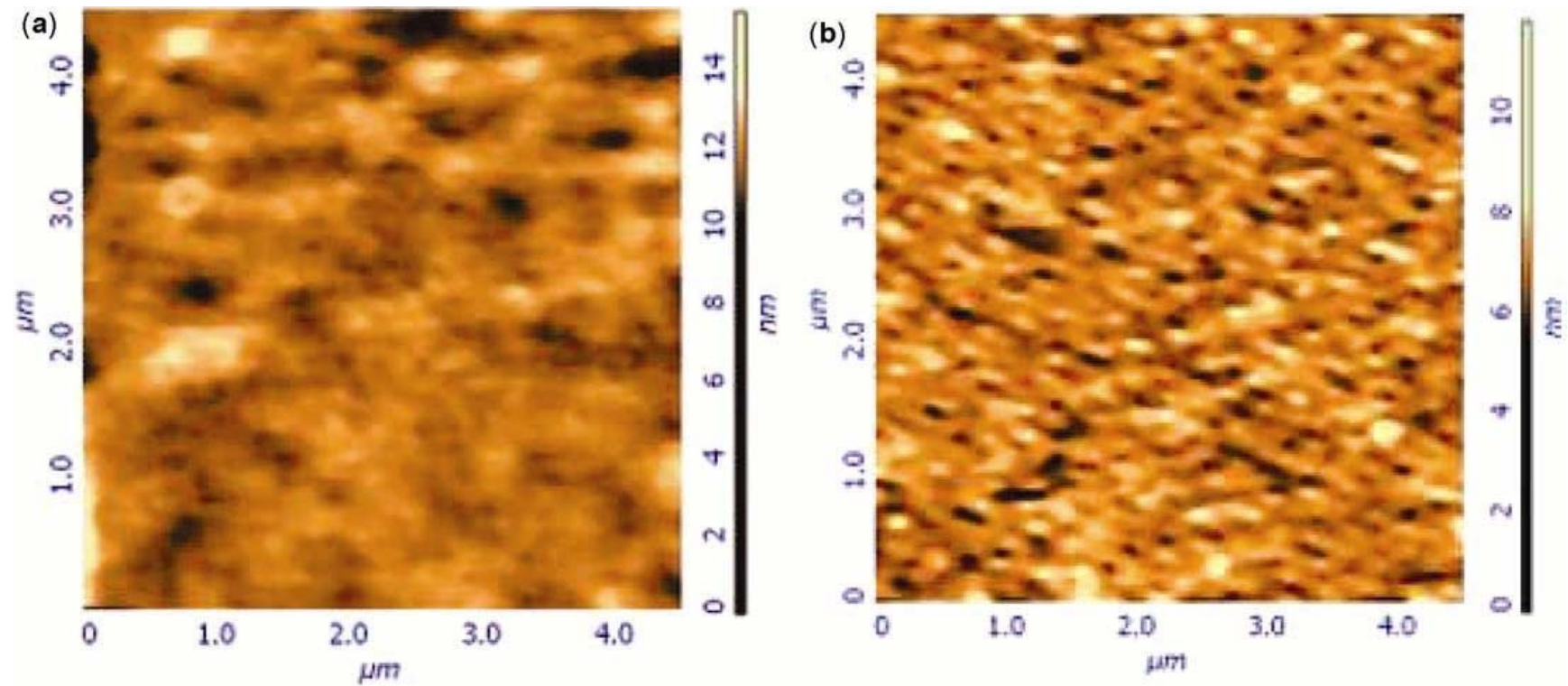

Figure 11. Typical grain structure of the sputtered deposited nickel film on $n$-type Si: (a) as deposited and (b) after annealing at $500^{\circ} \mathrm{C}$.

(I) The EN films prepared at lower $\mathrm{pH}$ value are of superior quality.

(II) The choice of annealing temperature is governed by the intended application of the film.

(III) In the case of electroless deposition a metal-semiconductor type contact is formed, while in a sputtered film it is of metal-insulating-semiconductor type. This difference is attributed to the hydrogen evolved during the electroless deposition process and its reaction with native surface oxide layer on silicon.

(IV) In EN films annealed at $900^{\circ} \mathrm{C}$, the presence of new diffraction peaks in the XRD pattern is observed. Further investigations are required to find their origin.

\section{References}

Brenner A and Riddell G E 1946 J. Res. Nat. Bur. Stand. 3731 Chow G M, Kurihara L K, Ma D, Feng C R, Schoen P E and Martinez M L J 1997 Appl. Phys. Lett. 702315
Haichuan M, Seok J and Lin R Y 2003 J. Electrochem. Soc. 150 C67

Jeon Y D and Paik K W 2002 IEEE Trans. Comp. Packag. Manuf. Technol. 25169

Libo L, Maozhong A and Gaohui W 2006 Surf. \& Coat. Technol. 2005102

Liu C M, Liu W L, Hsieh S H, Tsai T K, Chen W J and Wu S S 2006 Thin Solid Films 510102

Liu W L, Hsieh S H, Tsai T K and Chen W J 2005 Appl. Surf. Sci. 243259

Powder diffraction file No. 48-1339 JCPDS-ICDD, USA, 1993

Powder diffraction file No. 77-2107 JCPDS-ICDD, USA

Powder diffraction file No. 87-0712 JCPDS-ICDD, USA

Powder diffraction file No. 14-0481 JCPDS-ICDD, USA

Powder diffraction file No. 78-0429 JCPDS-ICDD, USA

Powder diffraction file No. 85-1977 JCPDS-ICDD, USA

Ralston J, Larson I, Rutland M W, Feiler A A and Kleijn M 2005 Pure Appl. Chem. 772149

Wonhee L, Jinhyung L, Joong D B, Chang S B and Dong K K 2001 Scr. Mater. 4497 